www.jmscr.igmpublication.org

Impact Factor (SJIF): 6.379

Index Copernicus Value: 79.54

ISSN (e)-2347-176x ISSN (p) 2455-0450

crossrefDOI: https://dx.doi.org/10.18535/jmscr/v6i8.36

Journal Of Medical Science And Clinical Research

\title{
Salvage surgery versus primary surgery for buccal mucosal squamous cell carcinoma and the need for neck dissection
}

\author{
Authors \\ Dr Jeyashanth Riju ${ }^{1}$, Dr Nebu Abraham George ${ }^{2 *}$, Dr Jagathnath Krishna KM ${ }^{3}$ \\ ${ }^{1}$ MBBS, MS., Fellow in Head and Neck Surgical Oncology, Regional Cancer Centre, Trivandrum, Kerala, \\ India \\ Email: jjriju@yahoo.co.in, https://orcid.org/0000-0003-4750-8111 \\ ${ }^{2} \mathrm{MS}$ (Gen Surgery), DNB (Gen Surgery), MRCS(Ed), DNB(Surg Oncology), Associate Professor, \\ Department of Surgical Oncology, Regional Cancer Centre, Trivandrum \\ ${ }^{3} \mathrm{Ph} . \mathrm{D}$, Assistant Professor, Department of Biostatistics, Regional Cancer Centre, Trivandrum. \\ Email: jagath.krishna@gmail.com \\ *Corresponding Author \\ Dr Nebu Abraham George, MS(Gen Surgery), DNB (Gen Surgery), MRCS(Ed), DNB(Surg Oncology) \\ Associate Professor, Department of Surgical Oncology, Regional Cancer Centre, Trivandrum, Kerala, India \\ 695011 \\ Phone +917406020741, Email: georgeabe@gmail.com
}

\begin{abstract}
Background: Buccal mucosal squamous cell carcinoma (BSCC) is the most common oral malignancy. $B S C C$ can be treated with Radiotherapy $(R T)$ or surgery or multimodality treatment. This article deals with $R T$ failure BSCC treated by surgery and its subsequent management.

Material and Methods: This is a retrospective analysis done in a tertiary care cancer center. The study included 162 patients, of which 35 were treated for $R T$ failure and 127 underwent a primary surgery. Histopathological factors like tumor stage, grade of differentiation, tumor front, skin involvement, bone involvement, depth of invasion, perineural invasion, lymphovascular emboli, primary resection margin in frozen section, nodal stage, extracapsular extension and lymph node ratio were analyzed and compared for LRR and DFS. Clinical neck nodal status was compared with pathological node status.

Results: 2 years DFS following salvage surgery was $54.3 \%$ and primary surgery was $71.7 \%$. Following $R T$, tumor tends to be poorly differentiated $(p=0.036)$ and with more incidence of perineural invasion $(p=0.043)$. Nodal involvement was less in salvage group (11.4\%) but when present, more than 1 nodal station got involved. The accuracy of finding a significant node by palpation in salvage patients was $14.28 \%$ compared to $54.3 \%$ in a primary setting.

Conclusion: BSCC following RT had a poor prognosis. Hence primary surgery must be considered over RT for BSCC. Cervical node palpation was not accurate in salvage patients. Following imaging, if neck dissection is indicated, modified radical neck dissection is to be performed.

Keywords: Buccal mucosa, Oral cancer, Squamous cell carcinoma, Neck node, Disease free survival, Loco regional recurrence.
\end{abstract}




\section{Introduction}

Oral cancer is the most common malignancy affecting developing countries like India wherein buccal mucosal squamous cell carcinoma (BSCC) is the most common cancer subsite. The primary reason being pan chewing, which is a combination of betel leaf, lime, areca nut and tobacco. Pan chewing promotes oral submucosal fibrosis, which predisposes to BSCC. ${ }^{1,2}$

BSCC is an aggressive cancer, treatment for which is mainly surgery followed by radiotherapy (RT) when indicated. In India RT mainly plays an important role in the treatment of early stages of BSCC especially when bone and skin is not involved. The reason for patients to choose RT over surgery is because of anticipated fear of surgical procedure especially when told about wide excision, bone resection, neck dissection and need for reconstruction. Also, patients get deceived by the thought of reduced morbidity in RT compared to surgery following treatment. A study by Nair et al. in BSCC treated with RT showed a 3 years disease-free survival (DFS) of $42 \% .^{3}$ Thus most of the patients treated with RT will require a salvage surgery. Salvage surgery following RT is a complex procedure because clinical judgment regarding extent of resection and disease infiltration is highly unpredictable. This leads to a wider surgical excision than normal resection.

Locoregional recurrence remains the common cause of treatment failure in oral cavity cancers, ${ }^{4}$, especially in BSCC. This can be prevented only by an efficient management during primary surgery and a more aggressive approach in salvage surgery. ${ }^{5}$

Study of salvage surgeries is not widely available, especially for BSCC. There is no consensus regarding the need for neck dissection or extent of neck dissection that is required in salvage setting. We have retrospectively analyzed the data of primary surgeries and salvage surgeries that were performed in a curative intend to explore the optimal management of neck in BSCC salvage surgery.

\section{Materials and Method}

This retrospective study was carried out in Regional Cancer Centre, Trivandrum, which is a tertiary care cancer center. All patients with BSCC who were operated with a curative intent between January 2014 and December 2015 were considered. Institutional review board approval was taken. Patients were grouped into two. Group I included patients who underwent salvage surgery for biopsy proven BSCC following a failed RT. Group II included patients who underwent primary surgery for biopsy proven BSCC with or without adjuvant RT. Patients who expired in the immediate post operative period and those who lost to followup were excluded from the study. All case sheets were analyzed for clinical neck status, pathological factors and locoregional recurrence (LRR).

175 patients underwent surgery for BSCC among whom 162 met the inclusion criteria. Group I included 35 patients (21.6\%) and group II included 127 patients $(78.4 \%)$.

Patients underwent wide excision of the lesion with or without resection of adjacent bone, aiming for a gross resection margin of $1 \mathrm{~cm}$. Frozen section study was done for resection margin status, margin less than $1 \mathrm{~mm}, 2$ to $5 \mathrm{~mm}$ and more than $5 \mathrm{~mm}$ were grouped as involved, close and clear respectively. Re-excision was done when the margin was less than $5 \mathrm{~mm}$. Neck dissection was done as per surgeons clinical judgment which included supraomohyoid neck dissection or extended supraomohyoid neck dissection or modified radical neck dissection. Reconstruction was done either by primary closure, splitthickness skin grafting, buccal fat pad cover, nasolabial flap, submental flap or pectoralis major myocutaneous flap reconstruction.

Adjuvant RT was planned based on advanced clinical stage or advanced pathological stage or based on risk factors, keeping in mind the performance status of the patient. Staging was done according to the American Joint Committee on Cancer (AJCC) 7th staging system for cancer of the oral cavity. 
Histopathological examination was done and following tumor-related factors were considered: pathological tumor stage, grade of differentiation, tumor front, skin involvement, bone involvement, depth of invasion, perineural invasion, lymphovascular emboli, primary resection margin in frozen section. Lymph nodes were analyzed for nodal stage, extracapsular extension and lymph node ratio (defined as the ratio between the number of pathological cervical lymph nodes and the total number of resected cervical lymph nodes). ${ }^{6}$ The site of recurrence was noted along with the duration of recurrence from the date of surgery. ${ }^{7}$ Local recurrence was defined as the lesion at the site or adjacent to the primary tumor, which was completely treated. Regional recurrence is defined as palpable nodal mass in the ipsilateral or contralateral side of neck after completion of treatment. ${ }^{8}$

\section{Statistical Analysis}

The categorical variables were summarized using frequency and proportion, and continuous variables using mean \&amp; standard deviation. The associations between categorical variables were assessed using Chi-square/ Fisher's exact test. Diagnostic accuracy was assessed using sensitivity, specificity, positive predictive value and negative predictive value. The survival probability was estimated using Kaplan-Meier estimate and comparison were done using Log Rank test. A p-value $<0.05$ was considered to be significant.

\section{Results}

Mean age of patients in group I was53 +/- 10.1 (range 30 to 70 years), which included 29 (82.9\%) men and $6(17.1 \%)$ women. Mean age of patients in group II was $54.9+/-10$ (range 23 to 76 years) which includes 102(80.3\%) men and 25(19.7\%). Male to female ratio was around 5:1 in both groups. With a median followup of 41months, recurrence was noted in $16(45.7 \%)$ in group I in which $5(31.3 \%)$ recurred in primary site,
$9(56.3 \%)$ in the neck and second primary and distant metastasis were noted in one patient each. In group II 41(32.3\%) had recurrence, among which $11(26.8 \%)$ recurred in primary site, 16 (39\%) in neck site, $7(17.1 \%)$ had second primary where one was in oropharynx and rest in oral cavity and 7(17.1\%) developed distant metastasis (lungs- 5, bone -2). Two years DFS(Fig. 1/Table 1) in group 1 was $54.3 \%$ and group II was $71.7 \%$, though this was not statistically significant $(\mathrm{p}=0.081)$.

Twenty-seven patients (77.1\%) in group I and 107 patients $(84.3 \%)$ in group II underwent neck dissection. Post surgery only one $(2.9 \%)$ in group I needed RT whereas $100(78.7 \%)$ in group II received RT.

On comparison of various factors (Table 2), it was found that disease in group I was poorly differentiated (20\%) compared to group II which were mostly well differentiated $(31.5 \%)$ and this difference was statistically significant $(\mathrm{p}=0.036)$. Perineural invasion was more common in group I compared to group II $(54.3 \%$ Vs35.4\%) with a significant $p$-value of 0.043 . Clinically palpable node was seen frequently in group II than in group I (54.3\% Vs $14.3 \%)$ and this difference was statistically significant $(\mathrm{p}<0.0001)$.

Pathological node was noted in 4(11.4\%) in group I compared to $47(37 \%)$ in group II with a significant p-value of 0.009 . Among those with node involvement, extracapsular spear (ECS) was noted in $2(5.7 \%)$ in group I compared to 31 $(24.4 \%)$ in group II with a significant p-value of 0.016 .

Accuracy of detecting a node (Table 3 ) which is pathologically positive $(\mathrm{N}+)$ by palpation was $14.28 \%$, with a sensitivity of zero and specificity of $83.37 \%$ in Group I. In group II accuracy of detecting $\mathrm{N}+$ node by clinical palpation was $54.3 \%$, with a sensitivity of $80.85 \%$ and specificity of $61.25 \%$. Among the 4 patients who got nodal recurrence in group I, two had level V nodal involvement and all had more than one nodal station involvement. 
Fig 1 DFS Salvage surgery versus Primary surgery

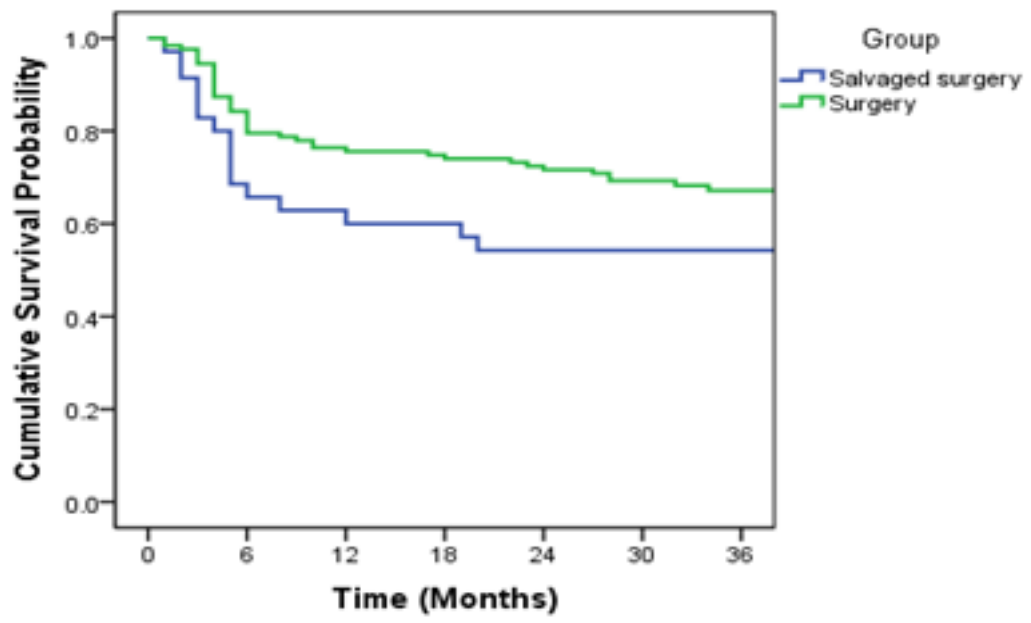

Table 1: DFS Salvage versus primary surgery

\begin{tabular}{|c|c|c|c|c|c|}
\hline \multirow{2}{*}{$\begin{array}{l}\text { Time } \\
\text { (Months) }\end{array}$} & \multicolumn{2}{|c|}{ Salvage Surgery } & \multicolumn{2}{|c|}{ Primary surgery } & \multirow[t]{2}{*}{$\mathrm{P}$-value } \\
\hline & $\begin{array}{c}\text { Survival } \\
\text { Probability }(\%)\end{array}$ & SE (\%) & $\begin{array}{c}\text { Survival } \\
\text { Probability }(\%)\end{array}$ & $\mathrm{SE}(\%)$ & \\
\hline 12 & 60.0 & 8.3 & 75.6 & 3.8 & \multirow[t]{3}{*}{0.081} \\
\hline 24 & 54.3 & 8.4 & 71.7 & 4.0 & \\
\hline 36 & 54.3 & 8.4 & 67.2 & 4.2 & \\
\hline
\end{tabular}

Table 2: Comparison of Group I Vs Group II.

\begin{tabular}{|c|c|c|c|c|}
\hline Variables & & Group I $(n=35)$ & Group II(n=127) & P Value \\
\hline \multirow[t]{2}{*}{ Sex } & Male & $29(82.9)$ & $102(80.3)$ & 0.735 \\
\hline & Female & $6(17.1)$ & $25(19.7)$ & \\
\hline \multirow[t]{2}{*}{ Age(Median =55 years) } & $<$ Median & $21(60)$ & $63(49.6)$ & 0.276 \\
\hline & $>$ Median & $14(40)$ & $64(50.4)$ & \\
\hline \multirow[t]{3}{*}{ Grade } & 1 & $6(17.1)$ & $40(31.5)$ & 0.036 \\
\hline & 2 & $22(62.9)$ & $78(61.4)$ & \\
\hline & 3 & $7(20)$ & $9(7.1)$ & \\
\hline \multirow[t]{2}{*}{ Tumour Front } & Cohesive & $5(14.3)$ & $22(17.3)$ & 0.665 \\
\hline & Non cohesive & $30(85.7)$ & $105(82.7)$ & \\
\hline \multirow[t]{2}{*}{ T stage } & Early(T1/T2) & $22(62.9)$ & $94(74)$ & 0.209 \\
\hline & Late(T3/T4) & $13(37.1)$ & $33(26)$ & \\
\hline \multirow[t]{3}{*}{ N Stage } & 0 & $31(88.6)$ & $80(63)$ & 0.009 \\
\hline & 1 & $0(0)$ & $14(11)$ & \\
\hline & 2 & $4(11.4)$ & $33(26)$ & \\
\hline \multirow{2}{*}{ Skin Infiltration } & Absent & $7(20)$ & $28(80)$ & 0.120 \\
\hline & Present & $13(10.2)$ & $114(89.8)$ & \\
\hline \multirow{2}{*}{ Bone Infiltration } & Absent & $30(85.7)$ & $113(89)$ & 0.595 \\
\hline & Present & $5(14.3)$ & $14(11)$ & \\
\hline \multirow[t]{2}{*}{ PNI } & Absent & $16(45.7)$ & $82(64.6)$ & 0.043 \\
\hline & Present & $19(54.3)$ & $45(35.4)$ & \\
\hline \multirow[t]{2}{*}{ LVE } & Absent & $35(100)$ & 124(97.6) & 1.00 \\
\hline & Present & $0(0)$ & $3(2.4)$ & \\
\hline \multirow[t]{2}{*}{ Nodal ECS } & Absent & $33(94.3)$ & $96(75.6)$ & 0.016 \\
\hline & Present & $2(5.7)$ & $31(24.4)$ & \\
\hline \multirow[t]{2}{*}{ Clinical palpable node } & Absent & $30(85.7)$ & $58(45.7)$ & 0.0001 \\
\hline & Present & $5(14.3)$ & $69(54.3)$ & \\
\hline \multirow[t]{3}{*}{ Frozen surgical margin } & $<0.1 \mathrm{~cm}$ & $1(2.9)$ & $6(4.7)$ & 0.672 \\
\hline & $0.1-0.5 \mathrm{~cm}$ & $15(42.9)$ & $63(49.6)$ & \\
\hline & $>0.5 \mathrm{~cm}$ & $19(54.3)$ & $58(45.7)$ & \\
\hline \multirow[t]{3}{*}{ Depth of invasion } & $<0.5$ & $12(34.3)$ & $42(33.1)$ & 0.253 \\
\hline & 0.51 to $1.0 \mathrm{~cm}$ & $13(37.1)$ & $54(42.5)$ & \\
\hline & $>1.0 \mathrm{~cm}$ & $10(28.6)$ & $31(24.4)$ & \\
\hline \multirow[t]{2}{*}{ Recurrence } & Absent & $19(54.3)$ & $86(67.7)$ & 0.141 \\
\hline & Present & $16(45.7)$ & $41(32.3)$ & \\
\hline \multirow[t]{2}{*}{ Node Ratio } & Upto 12 & $33(94.3)$ & $106(83.5)$ & 0.169 \\
\hline & $>12$ & $2(5.7)$ & $21(16.5)$ & \\
\hline \multirow[t]{2}{*}{ Radiotherapy } & Given & $1(2.9)$ & $100(78.7)$ & 0.0001 \\
\hline & Not given & $34(97.1)$ & $27(21.3)$ & \\
\hline
\end{tabular}


Table 3: Clinical Vs Pathological neck node correlation:

\begin{tabular}{|c|c|c|c|c|c|c|}
\hline \multicolumn{3}{|l|}{ Group } & \multicolumn{2}{|c|}{ Pathological node } & \multirow[t]{2}{*}{ Total } & \multirow[t]{2}{*}{ P-value } \\
\hline & & & Absent & Present & & \\
\hline \multirow{3}{*}{$\begin{array}{l}\text { Salvage } \\
\text { surgery }\end{array}$} & \multirow{2}{*}{$\begin{array}{l}\text { Clinical Neck } \\
\text { Node }\end{array}$} & Absent & $26(86.7 \%)$ & $4(13.3 \%)$ & $30(100.0 \%)$ & \multirow[t]{3}{*}{1.00} \\
\hline & & Present & $5(100.0 \%)$ & $0(0)$ & $5(100.0 \%)$ & \\
\hline & \multicolumn{2}{|c|}{ Total } & $31(88.6 \%)$ & $4(11.4 \%)$ & $35(100.0 \%)$ & \\
\hline \multirow{3}{*}{$\begin{array}{l}\text { Primary } \\
\text { Surgery }\end{array}$} & \multirow{2}{*}{$\begin{array}{c}\text { Clinical Neck } \\
\text { Node }\end{array}$} & Absent & $49(84.5 \%)$ & $9(15.5 \%)$ & $58(100.0 \%)$ & \multirow[t]{3}{*}{0.0001} \\
\hline & & Present & $31(44.9 \%)$ & $38(55.1 \%)$ & $69(100.0 \%)$ & \\
\hline & \multicolumn{2}{|c|}{ Total } & $80(63.0 \%)$ & $47(37.0 \%)$ & $127(100.0 \%)$ & \\
\hline \multirow[t]{3}{*}{ Total } & \multirow{2}{*}{$\begin{array}{l}\text { Clinical Neck } \\
\text { Node }\end{array}$} & Absent & $75(85.2 \%)$ & $13(14.8 \%)$ & $88(100.0 \%)$ & \multirow[t]{3}{*}{0.0001} \\
\hline & & Present & $36(48.6 \%)$ & $38(51.4 \%)$ & $74(100.0 \%)$ & \\
\hline & \multicolumn{2}{|c|}{ Total } & $111(68.5 \%)$ & $51(31.5 \%)$ & $162(100.0 \%)$ & \\
\hline
\end{tabular}

Fig 2: DFS based on tumor stage $(n=162)$. $p$-value $=0.054$

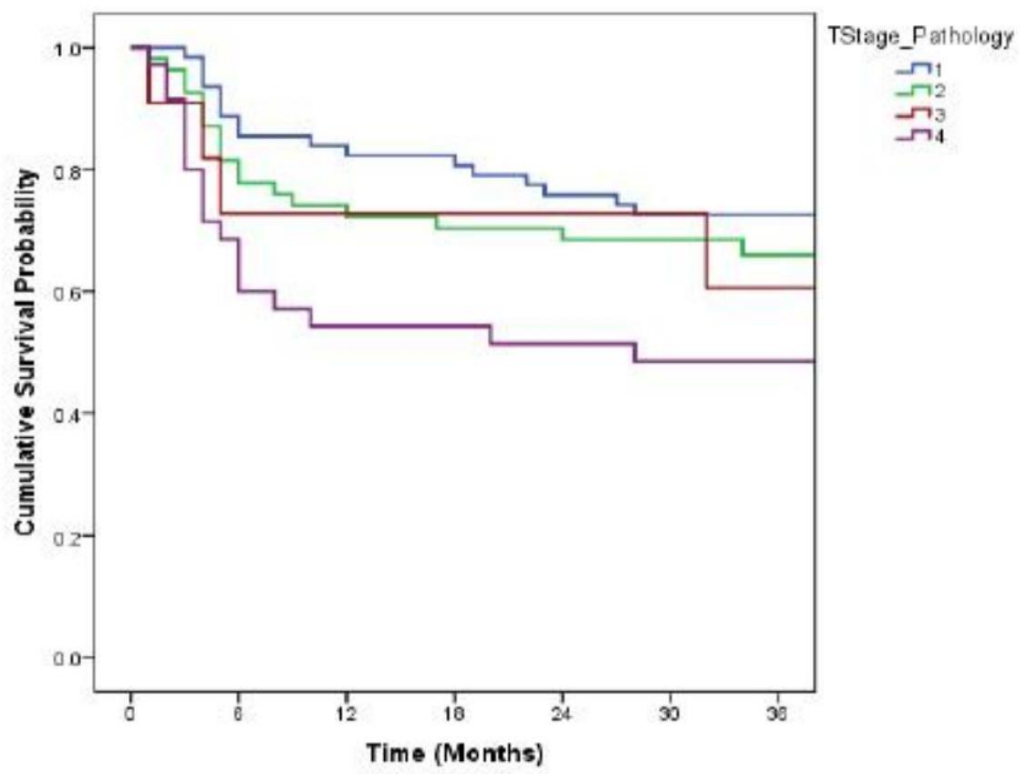

\section{Discussion}

Oral cancers are the sixth most common cancer globally which leads to 200,000 deaths annually and an addition of 575,000 new cases each year. ${ }^{5} \mathrm{BSCC}$ is most common malignancy in oral cavity in India, which commonly affects male gender in fifth decade. ${ }^{9}$

BSCC is a very aggressive cancer, which is well documented in the Western literature, this is mainly because of the poor anatomical barrier which allows an easy tumor spread to buccal fat pad even in an early tumor. Study sieczka et al. showed LRR of $40 \%$ in T1/T2 BSCC even when margins were free when treated by surgery alone. ${ }^{10}$ Strome et al. had a $100 \%$ recurrence in 2 years follow up for $\mathrm{T} 1 / \mathrm{T} 2$ disease treated by surgery. ${ }^{11}$ The study by Iyer et al. in T1/T2/T3 BSCC with surgery alone showed a 3-year DFS of $77 \%$ and most of the recurrence was within 2 years. ${ }^{12}$ In our study, we found a DFS of $75.8 \%$ and $68.5 \%$ in pathological stage $\mathrm{I}(62$ patients, $38 \%$ ) and II (54 patients,33\%) respectively (Fig. 2 ), which is comparable to the study by Iyer et al. This study shows the high effectiveness of surgery in BSCC in Indian population. Relative frequent performance of the procedure by surgeons and frozen section study by the pathologist, might be a reason for better DFS.

Nair et al. in 1988 found that with only RT, 3 years DFS of $73 \%, 47 \%, 42.5 \%$ and $18 \%$ for T1, T2, T3 and T4 disease respectively. ${ }^{3}$ Most of our T4 cases which was taken for primary RT had masticatory space involvement.

With respect to tumor histopathology, it was noted that following RT the disease spectrum changes towards poor differentiation and a higher chance for perineural invasion. This further deteriorates the prognosis and adding to it, these patients will 
solely depend on surgery with no adjuvant treatment possible. Thus the patient undergoing a primary multimodal treatment (71.7) had a better DFS compared to those who underwent salvage surgery (54.3) and this was better compared to patients who received RT alone $(42 \%)^{3}$. Thus surgery or combined surgery with postoperative $\mathrm{RT}$ is the recommended treatment for BSCC. ${ }^{13}$ Randomised control trial by Mishra et al. stressed the importance of RT of advanced BSCC. ${ }^{14}$ Even though our figures were good, DFS comparing salvage surgery patients and primary surgery patients did not reach a statistical significance because of less number of patients in group I.

Palpation of neck has an accuracy of 59\% in N0 neck and $79 \%$ in $\mathrm{N}+$ neck. ${ }^{15} \mathrm{In}$ our center, we routinely consider palpatory method. In the experienced hand, depth of node palpation is around $1 \mathrm{~cm} .{ }^{16}$ Neck examination following RT is highly misleading, due to post RT changes in the neck, palpation of nodes will be very difficult and atherosclerotic vessels might give a false impression of node. ${ }^{17}$ In our study, the accuracy was $54.3 \%$ for palpated node to have $\mathrm{N}+$ disease with a sensitivity of $80.85 \%$ and specificity of $61.25 \%$. But accuracy fell down to $14.28 \%$ in patients who had prior RT. Thus palpation is highly inaccurate and should not be relied upon, especially in post-RT cases, thus indicating an appropriate imaging modality.

Neck dissection in salvage BSCC still remains a debate. Neck dissection is considered electively when the risk of occult metastasis exceeds 15$20 \% .{ }^{15}$ Oral cavity malignancy frequently metastasizes to level I-III nodal station. Level IV and $\mathrm{V}$ involvement are infrequent $(9 \%$ and $2 \%$ respectively). ${ }^{18}$ Further, superselective neck dissecttion (SSND) might be of good value in treatment of head and neck malignancy following radiation ${ }^{19}$ but the role of such dissection in salvage surgery still remains a question. In our study, it was noted that only $11.4 \%$ patient in the salvage surgery group had $\mathrm{N}+$ disease compared to $37 \%(\mathrm{~N} 1 / \mathrm{N} 2)$ in the primary surgery group and the chance of extracapsular spread also remained lower(5.7\% Vs $24.4 \%)$. Thus still questioning the need for neck dissection.

SSND will not give a better outcome in salvage surgery in BSCC, because $100 \%$ of our cases which were node positive $(\mathrm{N}+)$ had more than 1 node involvement in a minimal of two levels, 50\% of the cases which were $\mathrm{N}+$ had level $\mathrm{V}$ node involvement. Thus a SSND would hamper LRR and DFS for an aggressive tumor-like BSCC. Hence MRND would be the procedure of choice whenever neck dissection is indicated. Thus a routine imaging should be considered in a post-RT patient before salvage surgery and if any node is positive, an ipsilateral MRND is to be considered This study tells about the change in the spectrum of disease following RT, how to manage nodal status, the pattern of recurrence and DFS. The deficit in this study was it was a retrospective study and the number of patients in the salvage surgery group was less compared to group II. So further large prospective study might be considered to overcome the deficits.

\section{Conclusion}

Primary surgery in early disease and multimodal treatment in advanced disease will be the choice of treatment for BSCC. Surgery following RT is complicated because the disease tends to be more aggressive, normal anatomy in the surgical site will be altered and non availability for further adjuvant therapy, thus ultimately leading to a poor prognosis. Imaging is preferred to exclude nodal involvement after RT and if a suspicious node is encountered ipsilateral MRND is to be considered. Neck dissection can be avoided otherwise.

\section{Financial Disclosure - Nil \\ Conflict of Interest - Nil.}

\section{Reference}

1. Murthy V, Agarwal JP, Laskar SG, Gupta T, Budrukkar A, Pai P, Chaturvedi P, Chaukar D, D'Cruz A. Analysis of prognostic factors in 1180 patients with oral cavity primary cancer treated with definitive or adjuvant radiotherapy. 
Journal of cancer research and therapeutics. $2010 \mathrm{Jul}$ 1;6(3):282.

2. Niu LX, Feng Z, Li JN, Li CZ, Peng X, Guo CB. Prognostic factors of squamous cell carcinoma of the buccal mucosa: a retrospective study of 168 cases in North China. Journal of Oral and Maxillofacial Surgery. 2014 Nov 1;72(11):2344-50.

3. Krishnan Nair M, Sankaranarayanan R, Padmanabhan TK. Evaluation of the role of radiotherapy in the management of carcinoma of the buccal mucosa. Cancer. 1988 Apr 1;61(7):1326-31.

4. Brockstein B, Haraf DJ, Rademaker AW, Kies MS, Stenson KM, Rosen F, Mittal BB, Pelzer H, Fung BB, Witt ME, Wenig B. Patterns of failure, prognostic factors and survival in locoregionally advanced head and neck cancer treated with concomitant chemoradiotherapy: a 9-year, 337-patient, multi-institutional experience. Annals of oncology. 2004 Aug 1;15(8):1179-86.

5. Padma R, Thilagavathi R, Sundaresan S. Survival outcomes of buccal mucosa carcinoma patients with multimodal therapy: An institutional study. International Journal of Nutrition, Pharmacology, Neurological Diseases. 2016 Apr 1;6(2):76.

6. Safi AF, Grandoch A, Nickenig HJ, Zöller JE, Kreppel M. Importance of lymph node ratio for locoregional recurrence of squamous cell carcinoma of the buccal mucosa. Head \& neck. 2017 Dec;39(12):2488-93.

7. Pandey A, Desai A, Ostwal V, Patil V, Kulkarni A, Kulkarni R, Patil N, Chaukar D, Prabhash K, Banavali SD. Outcome of operable oral cavity cancer and impact of maintenance metronomic chemotherapy: A retrospective study from rural India. South Asian journal of cancer. 2016 Apr;5(2):52.

8. Singhania V, Jayade BV, Anehosur V, Gopalkrishnan K, Kumar N. Carcinoma of buccal mucosa: A site specific clinical audit. Indian journal of cancer. 2015 Oct 1;52(4):605.

9. Pathak KA, Nason R, Talole S, Abdoh A, Pai P, Deshpande M, Chaturvedi P, Chaukar D, D'Cruz A, Bhalavat R. Cancer of the buccal mucosa: a tale of two continents. International journal of oral and maxillofacial surgery. 2009 Feb 1;38(2):146-50.

10. Sieczka E, Datta R, Singh A, Loree T, Rigual N, Orner J, Hicks Jr W. Cancer of the buccal mucosa: are margins and $\mathrm{T}$ stage accurate predictors of local control? American journal of otolaryngology. 2001 Nov 1;22(6):395-9.

11. Strome SE, To W, Strawderman M, Gersten K, Devaney KO, Bradford CR, Esclamado RM. Squamous cell carcinoma of the buccal mucosa. Otolaryngology-Head and Neck Surgery. 1999 Mar;120(3):375-9.

12. Ganpathi Iyer S, Pradhan SA, Pai PS, Patil S. Surgical treatment outcomes of localized squamous carcinoma of buccal mucosa. Head \& Neck: Journal for the Sciences and Specialties of the Head and Neck. 2004 Oct;26(10):897-902.

13. Dixit S, Vyas RK, Toparani RB, Baboo HA, Patel DD. Surgery versus surgery and postoperative radiotherapy in squamous cell carcinoma of the buccal mucosa: a comparative study. Annals of surgical oncology. 1998 Sep 1;5(6):502-10.

14. Mishra RC, Singh DN, Mishra TK. Postoperative radiotherapy in carcinoma of buccal mucosa, a prospective randomized trial. European journal of surgical oncology. 1996 Oct 1;22(5):502-4.

15. Van den Brekel MW, Castelijns JA, Stel HV, Golding RP, Meyer CJ, Snow GB. Modern imaging techniques and ultrasound-guided aspiration cytology for the assessment of neck node metastases: a prospective comparative study. European 
archives of oto-rhino-laryngology. 1993 Mar 1;250(1):11-7.

16. Ali S, Tiwari RM, Snow GB. False-positive and false-negative neck nodes. Head \& neck surgery. 1985 Nov; 8(2):78-82.

17. Xu J, Cao Y. Radiation-induced carotid artery stenosis: a comprehensive review of the literature. Interventional neurology. 2013;2(4):183-92.

18. Suárez C, Rodrigo JP, Robbins KT, Paleri V, Silver CE, Rinaldo A, Medina JE, Hamoir M, Sanabria A, Mondin V, Takes RP. Superselective neck dissection: rationale, indications, and results. European Archives of Oto-Rhino-Laryngology. 2013 Nov 1;270(11):2815-21.

19. Robbins KT, Shannon K, Vieira F. Superselective neck dissection after chemoradiation: feasibility based on clinical and pathologic comparisons. Archives of Otolaryngology-Head \& Neck Surgery. 2007 May 1;133(5):486-9. 